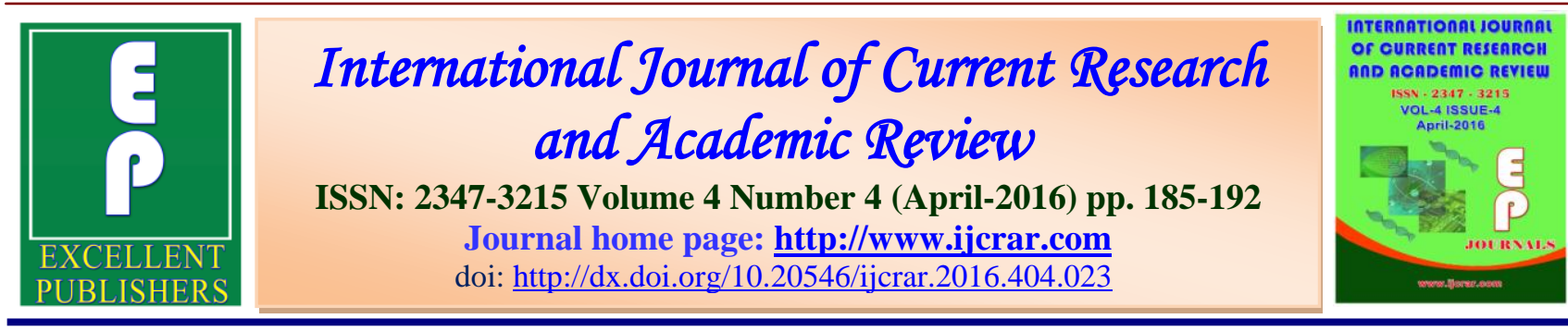

\title{
Enzymes of the De novo Pyrimidine Biosynthetic Pathway in Leishmania tropica
}

\section{Husain F. Hassan*}

Department of Biology, College of Science, University of Kirkuk, Iraq

*Corresponding author

\section{KEYWORDS}

Leishmania, de novo, pyrimidine, enzymes.

\section{A B S T R A C T}

The pathway of de novo pyrimidine biosynthesis in the amastigote and Promastigote forms of Leishmania tropica has been investigated.Both parasite forms contained all six enzyme activities. Carbamoyl phosphate synthase (CPSase) utilizes L- glutamine and not ammonia as the amine group donor. Dihydroorotate dehydrogenase (DHO-DHase) was found to be cytoplasmic, where as orotate phosphoribosyltransferase (OPRTase) and orotidylate decarboxylase (ODCase) were found to be particulate. N(phosphonacetyl)-L-aspartate, dihydro-5azaorotate, 5-azaorotate and 6-azaUMP were found to be a potent inhibitor of the aspartate transcarbamoylase (ATCase), DHO-DHase, OPRTase, and ODCase, respectively.

\section{Introduction}

There are two mechanisms by which an organism can produce pyrimidine nucleotides which are primarily required for nucleic acid synthesis. These are, the de novo biosynthesis from non-pyrimidine precursors (Fig.1) and salvage synthesis utilizing preformed exogenous pyrimidines. Much of the evidence to suggest the presence of the de novo pyrimidine biosynthesis in parasites has come mainly from studies of the composition of minimal defined media for the growth of organism (Kar et al., 1990, Kar, 1997) and the incorporation of radioactive biocarbonate and orotate into nucleic acid pyrimidine rings (3-5). Preliminary investigations have demonstrated the existence of a number of de novo enzymes in Leishmania mexicana amazonensis, L. m. mexicana and L. major (Hassan and Coombs, 1988; Berens et al., 1995; Carter et al., 2003; Hill et al., 1981; Hammond and Gutteridge, 1982; French et al., 2011; Wilson et al., 2012), vis, orotate phosphoribosyltransferase and orotidylate decarboxylase. I report here the presense of the activities of the six enzymes of the pyrimidine de novo biosynthetic pathway in L. tropica. The results indicate that these parasites have the potential for obtaining their pyrimidine requirements by de novo synthesis in a manner analogues to the closely related trypanosomal parasite. 
$2 \mathrm{ATP}+\mathrm{HCO}_{3}{ }^{-}+$Glutamine $+\mathrm{H}_{2} \mathrm{O}$

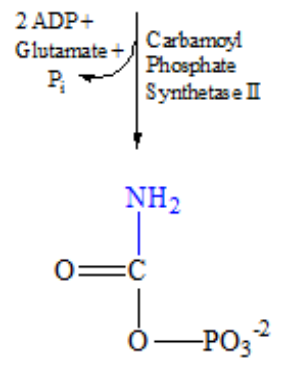

Carbamoyl Phosphate

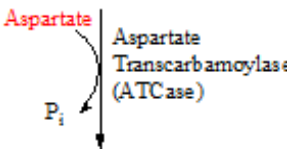<smiles>NC(=O)NC(CC(=O)O)C(=O)[O-]</smiles>

Carbamoyl A spartate

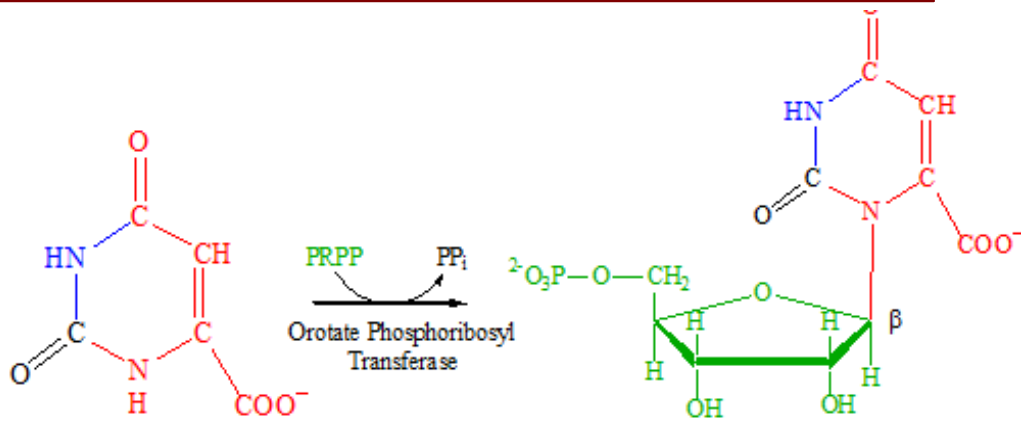

Orotate

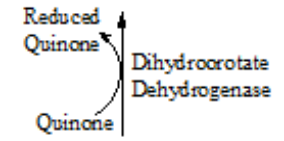<smiles>O=C1CC(C(=O)[O-])NC(=O)N1</smiles>

Dihydroorotate
Orotidine-5'-m onophosphate $(\mathrm{OMP})$
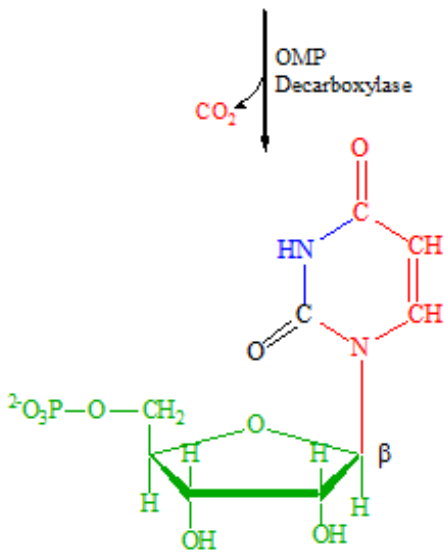

Uridine Monophosphate (UMP)

Fig. 1 Denovo pathway of uridine monophosphate

\section{Material and Methods}

\section{Isolation, cultivation and fractionation of cells}

Leishmania tropica amastigotes were isolated from lesion of NIH mice by a method involving Saponin Lysis of host cells, anion exchange chromatography and isopycnic centrifugation, which will be detailed in (10). Promastigote of L. tropica were grown in vitro in HOMEM medium, with $10 \%(\mathrm{v} / \mathrm{v})$ heat inactivated fetal calf serum at $26 \mathrm{C}^{\circ}$. Crude homogenates of cells in $0.25 \mathrm{M}$ sucrose were obtained by 3 cycles of freezing $\left(-180 \mathrm{C}^{\circ}\right)$ and thawing (30Co) and fractionated by centrifugation at 100000 $\mathrm{Xg}$ for $1 \mathrm{hr}$ to yield particulate and supernatant fractions.

\section{Enzymes assays}

Assays for carbamoylphosphate synthase (CPSase, EC 2.7.2.5), aspartate transcarbamoylase (ATCase, EC 2.1.3.2), dihydroorotase (DHOase, EC 3.5.2.3), dihydroorotate dehydrogenase (DHODHase, EC 1.3.3.1), ororate phosphoribosyltransferase (OPRTase, EC 2.4.2.10) and orotidine-5-phosphate decarboxylase (ODCase, EC 4.1.1.23) were based on published methods. Enzymes activities for these enzymes were measured at $26 \mathrm{C}^{\circ}$ and expressed as nmol product $/ \mathrm{min} / \mathrm{mg} \quad$ protein. Protein concentrations were measured by the Lowery method (Lowery et al., 1951) using bovine serum albumin as standard. The effect of $\mathrm{pH}$ (range 6.0 - 10.0) on reaction 
velocity was determined in $20 \mathrm{mM}$ Trismaleate-glycine buffer.

\section{Results and Discussion}

The activities of the six enzymes of pyrimidine biosynthesis de novo, CPSase, ATCase, DHOase, DHO-DHase, OPRTase and ODCase, were demonstrated in both promastigote and amastigote of L.tropica homogenates (Table 1). The CPSase activity measured was L-glutamine dependent. The addition of ammonium ions $(15 \mathrm{mM})$ did not stimulate the enzyme activity. Thus it seems that L.tropica contains only CPSase (II)glutamine dependent and totally lacks CPSase (I) ammonia dependent activity. The results indicated that the UTP phosphoribosyl pyrophosphate (PRPP) stimulate the activity by $15 \%$.

High activities of aspartate transcarbamoylase (ATCase) and dihydro-orotase (DHOase), the second and the third enzymes of the pyrimidine biosynthetic pathway, were detected in both promastigote and amastigote of L.tropica (Table 1). This pattern of low CPSase and high ATCase is typical of a number of organisms. Apparent Michaelis - Menten constant $(\mathrm{Km})$ values for both aspartate and carbamoylphosphate were determined for ATCase (Table 2). Substrate inhibition at concentrations above $10 \mathrm{mM}$ was observed for aspartate. This has been demonstrated for ATCase from other systems (Inagaki and Tatibana, 1970). Nphosphonacetyl-L-aspartate (PALA), was shown to be competitive inhibitor of promastigote and amastigote ATCase with $\mathrm{Ki}$ of $6 \mu \mathrm{M}$ and $9 \mu \mathrm{M}$, respectively (Table 2).

On the other hand, the $\mathrm{Km}$ value for dihydroorotate (L-DHO) was $0.76 \mathrm{mM}$ and $1.1 \mathrm{mM}$ for promastigote and amastigote DHOase respectively (Table 2). The activity of DHOase of both parasite forms did not inhibited by O-phenanthroline $(1 \mathrm{mM})$ and L-cysteine (1 mM).

The activity of dihydroorotate dehydrogenase (DHO-DHase) of promastigotes was shown to be five times higher t-han that of amastigotes (Table 1). The $\mathrm{Km}$ values for L-DHO were determined as $8.2 \mu \mathrm{M}$ and $16.1 \mu \mathrm{M}$ for promastigotes and amastigotes DHO-DHase, respectively (Table 2). The activity of DHO-DHase was inhibited by dihydro-5-azaorotate, an analog of L-DHO, with $\mathrm{Ki}$ values of $9.6 \mu \mathrm{M}$ and $18.1 \mu \mathrm{M}$ for promastigotes and amastigotes enzyme respectively (Table 2). DHO-DHase activity in the both parasite forms was not inhibited by cyanide $(5 \mu \mathrm{M})$ antimycin $\mathrm{A}$ $(0.1 \mathrm{mg} / \mathrm{ml})$ or amytal $(1 \mathrm{mM})$ indicating that the reaction was not coupled to the conventional respiratory chain.

Table.1 Specific activities of the enzymes of the pyrimidine biosynthetic pathway in Leishmania tropica

\begin{tabular}{|c|c|c|c|c|}
\hline \multirow{2}{*}{ Enzyme } & \multicolumn{2}{|c|}{ Promastigote } & \multicolumn{2}{c|}{ Amastigote } \\
\cline { 2 - 5 } & pH optimum & Specific activity & pH optimum & Specific activity $^{\mathbf{a}}$ \\
\hline CPSase II & 7.2 & $4.6 \pm 0.4$ & 7.2 & $4.1 \pm 0.5$ \\
\hline ATCase & 8.4 & $112 \pm 11$ & 8.0 & $98 \pm 13$ \\
\hline DHOase & 6.4 & $27 \pm 1$ & $6-6.5$ & $23 \pm 2$ \\
\hline DHO-DHase & 7.0 & $0.98 \pm 0.1$ & 7.0 & $0.21 \pm 0.03$ \\
\hline OPRTase & 7.5 & $0.14 \pm 0.04$ & 7.5 & $0.09 \pm 0.01$ \\
\hline ODCase & 8.0 & $1.96 \pm 0.1$ & 8.2 & $0.82 \pm 0.1$ \\
\hline
\end{tabular}

$\mathrm{a}=\mathrm{nmol} / \mathrm{min} / \mathrm{mg}$ protein; The figures represent mean $\pm \mathrm{SD}$ of three determinations 
Int.J.Curr.Res.Aca.Rev.2016; 4(4): 185-192

Table.2 Summary of kinetic data and inhibition constants for the L.tropica pyrimidine biosynthetic enzymes

\begin{tabular}{|c|c|c|c|c|}
\hline \multirow[b]{2}{*}{ Enzyme } & \multicolumn{2}{|c|}{ Promastigote } & \multicolumn{2}{|c|}{ Amastigote } \\
\hline & $\mathbf{K}_{\mathrm{m}}$ & $\mathbf{K}_{\mathrm{i}}$ & $\mathbf{K}_{\mathrm{m}}$ & $\mathbf{K}_{\mathbf{i}}$ \\
\hline \multicolumn{5}{|l|}{ CPSase II } \\
\hline Glutamine & $18 \mu \mathrm{M}$ & - & $24 \mu \mathrm{M}$ & - \\
\hline UTP & - & $720 \mu \mathrm{M}$ & - & $910 \mu \mathrm{M}$ \\
\hline \multicolumn{5}{|l|}{ ATCase } \\
\hline Aspartate & $2.1 \mathrm{mM}$ & - & $2.8 \mathrm{mM}$ & - \\
\hline Carbamoylphosphate & $11 \mu \mathrm{M}$ & - & $13 \mu \mathrm{M}$ & - \\
\hline PALA & - & $6 \mu \mathrm{M}$ & - & $9 \mu \mathrm{M}$ \\
\hline \multicolumn{5}{|l|}{ DHOase } \\
\hline L-DHO & $0.76 \mathrm{mM}$ & - & $1.1 \mathrm{mM}$ & - \\
\hline \multicolumn{5}{|l|}{ DHO-DHase } \\
\hline L-DHO & $8.2 \mu \mathrm{M}$ & - & $16.1 \mu \mathrm{M}$ & - \\
\hline Dihydro-5-azaorotate & - & $9.6 \mu \mathrm{M}$ & - & $18.1 \mu \mathrm{M}$ \\
\hline \multicolumn{5}{|l|}{ OPRTase } \\
\hline Orotate & $5.4 \mu \mathrm{M}$ & - & $4.2 \mu \mathrm{m}$ & - \\
\hline 5-Azaorotate & - & $6.8 \mu \mathrm{M}$ & - & $5.2 \mu \mathrm{M}$ \\
\hline \multicolumn{5}{|l|}{ ODCase } \\
\hline OMP & 0.92 & - & 0.71 & - \\
\hline UMP & - & $146 \mu \mathrm{M}$ & - & $124 \mu \mathrm{M}$ \\
\hline XMP & - & $115 \mu \mathrm{M}$ & - & $91 \mu \mathrm{M}$ \\
\hline 6-Aza-UMP & - & 0.46 & - & $0.37 \mu \mathrm{M}$ \\
\hline
\end{tabular}

Apparent $\mathrm{K}_{\mathrm{m}}$ values and inhibition constants $\left(\mathrm{K}_{\mathrm{i}}\right)$ for the most effective inhibitors tested, were determined from weighted regression procedures (19).

Table.3 Distribution of enzyme activities in Leishmania tropica between particulate and soluble fractions of cell extracts ${ }^{\mathrm{a}}$

\begin{tabular}{|c|c|c|c|c|}
\hline \multirow{2}{*}{ Enzyme } & \multicolumn{2}{|c|}{ Promastigote } & \multicolumn{2}{c|}{ Amastigote } \\
\cline { 2 - 5 } & $\mathbf{P}$ & $\mathbf{S}$ & $\mathbf{P}$ & S \\
\hline CPSase II & 0.39 & 2.8 & 0.26 & 2.3 \\
\hline ATCase & 0.47 & 4.2 & 0.41 & 3.8 \\
\hline DHOase & 0.3 & 4.9 & 0.07 & 1.8 \\
\hline DHO-DHase & 0.5 & 4.1 & 0.15 & 2.1 \\
\hline OPRTase & 1.6 & 0.05 & 1.2 & 0.04 \\
\hline ODCase & 1.6 & 0.05 & 1.4 & 0.06 \\
\hline
\end{tabular}

$\mathrm{a}=$ Crude homogenates were prepared as described in materials and methods, were centrifuged at 100000 $\mathrm{Xg}$ for $60 \mathrm{~min}$ at $4 \mathrm{C}^{\circ}$. The pellet was resuspended in a volume of preparation buffer equal to the supernatant recovered. The fractions produced were assayed for pyrimidine biosynthetic enzymes. The results are expressed as relative specific activities (\% total activity / \% total protein) in the particulate (P) and the soluble (S) fractions. 
The two enzymes that comprise the latter part of the pyrimidine biosynthetic pathway were found to be present in the crude homogenate of both parasite forms. The activity of orotidylate decarboxylase (ODCase) was significantly higher than the orotate phosphoribosyltransferase (OPRTase). The Km values for orotic acid was determined to be $5.4 \mu \mathrm{M}$ and $4.2 \mu \mathrm{M}$ for promastigotes and amastigotes OPRTase, respectively. The substrate analog, 5azaorotic acid, was demonstrated to be a competitive inhibitor with respect to orotic acid with $\mathrm{Ki}$ of $6.8 \mu \mathrm{M}$ and $5.2 \mu \mathrm{M}$ for promastigotes and amastigotes enzymes, respectively. On the other hand, the $\mathrm{Km}$ for orotidylic acid (OMP) was determined to be $0.92 \mu \mathrm{M}$ and $0.71 \mu \mathrm{M}$ for promastigotes and amastigotes ODCase respectively. As detailed in Table 2, the product of the reaction UMP was a weak inhibitor, 6-azaUMP a good inhibitor, and the purine nucleotide XMP, only a moderate inhibitor of the ODCase reaction in both parasite forms. It is of interest to note that the allopurinol and oxipurinol which inhibit human OPRTase and ODCase, did not have any marked inhibitory effect on the terminal two enzymes in the pathway from L.tropica. The distribution of the pyrimidine biosynthetic enzymes in the various cell fractions are shown in (Table 3). CPSase I, ATCase, DHOase and DHO-DHase were found to be predominantly in the supernatant fraction indicating the cytosolic nature of the enzymes. In contrast, the OPRTase and ODCase activity in L.tropica promastigotes and amastigotes were shown to be associated with the $100000 \mathrm{xg}$ pellet, indicating the particulate nature of the enzymes.

For the first time all the enzyme activities necessary for the de novo biosynthesis of UMP have been detected in crude homogenates of promastigote and amastigote forms of L.tropica, thus providing evidence that both parasite forms depends primarily on the de novo pathway as a source of pyrimidine. Notably CPSase II activity was observed. Carbamoyl phosphate systhase of L. tropica shares the properties of the synthase II of higher animals (Wahl et al., 1979) in that (a) it utilizes L-glutamine as source of ammonia; (b) it does not require $\mathrm{N}$-acetyl-L-glutamate; (c) it is localized in the cytosol fraction; (d) it is subject to feedback inhibition by pyrimidine nucleotides; (e) it is stimulated by PRPP.

As reported for all other sources, the highest specific activity was observed for ATCase. Its kinetic behavior appears to be similar to the enzyme from other systems (Ali et al., 2013). However, the inhibition by PALA is consistent with the idea that the measured activity was ATCase and not an artifact.

In common with other known pyrimidine biosynthetic pathways, CPSase II, ATCase and DHOase are soluble enzymes. In contrast to other cells, OPRTase and ODCase are particulate enzymes, not only in L.tropica (Table 3) but also in Trypanosoma cruzi in agreement with previous studies (Shi et al., 1999). Location of DHO-DHase in L.tropica is also unusual in that it is cytosolic. A soluble DHO-DHase has also been reported in other kinetoplastida and requires oxygen for activity but not sensitive to inhibition by cyanide or antimycin A. In contrast, in mammalian cells, DHO-DHase has been found to be membrane bound, mitochondrial and intimately connected to the repiratory chain to which it passes electron directly probably at the ubiquinone level (Ritt et al., 2013). The qualitative differences found between the last three enzymes of the pyrimidine de novo biosynthetic pathway in L.tropica and mammalian cells may make this area of 
metabolism a potentially useful target at which to aim in the search for much needed new antileishmanial drugs (Hassan, 2002).

\section{References}

Ali, J.A., Tagoe, D.N., Munday, J.C., Donachie, A., Morrison, L.J., de Koning, H.P. 2013. Pyrimidine biosynthesis is not an essential function for Trypanosoma brucei bloodstream forms. PLoS One, 8: e58034.

Ali, J.A., Tagoe, D.N., Munday, J.C., Donachie, A., Morrison, L.J., et al. 2013. Pyrimidine biosynthesis is not an essential function for Trypanosoma brucei bloodstream forms. PLoS One, 8: e58034.

Arakaki, T.L., Buckner, F.S., Gillespie, J.R., Malmquist, N.A., Phillips, M.A., Kalyuzhniy, O., Luft, J.R., Detitta, G.T., Verlinde, C.L., Van Voorhis, W.C., Hol, W.G., Merritt, E.A. 2008. Characterization of Trypanosoma brucei dihydroorotate dehydrogenase as a possible drug target. Structural, kinetic and RNAi studies. Mol. Microbiol., 68: 37-50.

Berens, R.L., Krug, E.C., Marr, J.J. 1995. Purine and pyrimidine metabolism. In Biochemistry of Parasitic Organisms and its Molecular Foundations (Marr, J.J. and Muller, M.eds) PP. 89-117. Academic Press.

Carter, N., Rager, N., Ullman, B. 2003. Purine and pyrimidine transport and metabolism, in Molecular and Medical Parasitology (Marr, J. J., and R. Komuniecki, eds) pp. 197-223, Academic Press Limited, London.

Fox, B.A., Bzik, D.J. 2002. De novo pyrimidine biosynthesis is required for virulence of Toxoplasma gondii. Nature, 415: 926-929.
French, J.B., Yates, P.A., Soysa, D.R., Boitz, J.M., Carter, N.S., Chang, B., Ullman, B., Ealick, S.E. 2011. The Leishmania donovani UMP synthase is essential for promastigote viability and has an unusual tetrameric structure that exhibits substratecontrolled oligomerization. J. Biol. Chem., 286: 20930-20941.

Hammond, D.J., Gutteridge, W.E. 1982. UMP synthesis in the kinetoplastida. Biochem. et Biophys. Acta, 718: 1-10.

Hashimoto, M., Morales, J., Fukai, Y., Suzuki, S., Takamiya, S., Tsubouchi, A., Inoue, S., Inoue, M., Kita, K., Harada, S., Tanaka, A., Aoki, T., Nara, T. 2012. Critical importance of the de novo pyrimidine biosynthesis pathway for Trypanosoma cruzi growth in the mammalian host cell cytoplasm. Biochem. Biophys. Res. Commun., 417: 1002-1006.

Hassan, H.F. 2002. Effect of some purine analog on growth and metabolism of Leishmania major promastigotes. The 2nd. Int Con. Biol. Sci., Egypt, PP. 51.

Hassan, H.F., Coombs, G.H. 1985. Leishmania mexicana: Purine metabolizing enzymes of amastigotes and promastigotes. Exp. Parasitol., 59: 139-150.

Hassan, H.F., Coombs, G.H. 1986. A comparative study of the purine and pyrimidine metabolizing enzymes of a range of trypanosomatid. Comp. Biochem. Physiol., 84 B: 217-223.

Hassan, H.F., Coombs, G.H. 1988. Purine and pyrimidine metabolism in parasitic protozoa. FEMS Microb. Rev., 54: 47-84.

Hill, J.K., Rogerson, G.W., Mclntosh, R.T., Ginger, C.D. 1981. The enzymes of pyrimidine biosynthesis in a range of parasitic protozoa and helminthes. Mol. Biochem. Parasit., 2: 123-134. 
Inagaki, A., Tatibana, M. 1970. Control of pyrimidine biosynthesis $\mathrm{n}$ mammalian tissues, Biochem. et Biophys. Acta, 220: 491-502.

Kar, K. 1997. Folic acid the essential supplement to brain heart infusion broth for cultivation and cloning of Leishmania donovani promastigotes. Parasit., 115: 231-235.

Kar, K., Mukerji, K., Nasker, K., Bhattacharya, A., Ghosh, D. 1990. Leishmania donovani : a chemically defined medium for cultivation and cloning of promastigotes and transformation of amastigotes to promastigotes. J. Protozool., 37: 277279.

Lowery, O.M., Rosenbrough, N., Farr, A.C., Randall, R.J. 1951. Protein measurement with folin phenol reagent. J. Biol. Chem., 193: 265-275.

Ritt, J.F., Raymond, F., Leprohon, P., Legare, D., Corbeil, J., Ouellette M. 2013. Gene amplification and point mutations in pyrimidine metabolic genes in 5-fluorouracil resistant Leishmania infantum. PLoS Negl. Trop. Dis., 7(11): 1-11.
Shi, W., Schramm, V.L., Almo, S.C. 1999. Nucleoside hydrolase from Leishmania major. Cloning, expression, catalytic properties, transition state inhibitors, and the 2.5A crystal structure. J. Biol. Chem., 274: 21114-21120.

Soysa, R., Wilson, Z.N., Elferich, J., Forquer, I., Shinde, U., Riscoe, M.K.,Yates, P.A., Ullman, B. 2013. Substrate inhibition of uracil phosphoribosyltransferase by uracil can account for the uracil growth sensitivity of Leishmania donovani pyrimidine auxotrophs. J. Biol. Chem., 288: 29954-29964.

Wahl, G.M., Padgett, R.A., Stark, G.R. 1979. Gene amplification causes overproduction of the first three enzymes of UMP synthesis in $\mathrm{N}$ (phosphonacetyl)-L-aspartateresistant hamster cells. J. Biol. Chem., 254: 8679-8689.

Wilson, Z.N., Gilroy, C.A., Boitz, J.M., Ullman, B., Yates, P.A. 2012. Genetic dissection of pyrimidine biosynthesis and salvage in Leishmania donovani. J. Biol. Chem., 287: 12759-12770.

\section{How to cite this article:}

Husain F. Hassan. 2016. Enzymes of the De novo Pyrimidine Biosynthetic Pathway in Leishmania tropica. Int.J.Curr.Res.Aca.Rev.4(4): 185-192. doi: http://dx.doi.org/10.20546/ijcrar.2016.404.023 